\title{
Modelos, formas e referências para os retábulos em Minas Gerais: o caso do tratado de Andrea Pozzo
}

\author{
Models, shapes and references for retables in Minas Gerais: the \\ case of Andrea Pozzo's treatise
}

\author{
AZIZ JOSÉ DE OLIVEIRA PEDROSA \\ Universidade do Estado de Minas Gerais \\ azizpedrosa@yahoo.com.br
}

\begin{abstract}
Resumo: Entre os anos de 1730 e 1760, as igrejas setecentistas de Minas Gerais (Brasil), tiveram seus espaços internos transformados por retábulos e relevos de madeira, que materializaram as tendências barrocas correntes em Portugal, denominadas por Robert Smith de "estilo joanino". Esse ciclo foi resultante do labor de oficiais portugueses, responsáveis pela produção de peças que contribuíram para propagar elementos formais e estéticos vinculados à arte desse período, na então Colônia brasileira. Reconhece-se que livros de arquitetura e gravuras circularam àquela época em Minas, incrementando as referências que constituíram o repertório artístico coevo. No domínio da arte local, no entanto, não foi devidamente mensurada a efetiva função exercida por essas fontes, tampouco foram examinados os nomes dos autores que podem ter exercido predominância nas orientações seguidas pelos artistas. Nesse sentido, este artigo tem como objetivo analisar a influência do tratado Perspectiva pictorum et architectorum (1717), de Andrea Pozzo (1642-1709), na construção e na formatação dos retábulos joaninos mineiros, conhecida a circulação desses livros entre entalhadores em exercício na região.
\end{abstract}

Palavras-chaves: Retábulos, estilo joanino, Andrea Pozzo, Barroco.

Abstract: Between 1730 and 1760, the $18^{\text {th }}$ century churches of Minas Gerais (Brazil) had their spaces transformed by retables and other wood ornaments that materialized the Portuguese baroque trends named by Robert Smith as "joanino" style. That cycle was the result of the work of Portuguese artists responsible for producing pieces that contributed in disseminating formal and aesthetic elements linked to Brazilian colonial art. It's known that architecture books and engravings circulated at that moment in Minas increasing the references of the artistic repertoire then. However, the effective role of these sources to the local art wasn't properly examined neither were the authors that might have influenced the instructions which current artitsts were following. Therefore, this article aims to analyze the influence of Andrea Pozzo's treatise Perspectiva pictorum et architectorum (1717) in the construction and format of joaninos retables in Minas Gerais, since the use of these books by the carvers of the region has already been established.

Keywords: Retables, Joanino style, Andrea Pozzo, Baroque.

Recibido: 17 de enero de 2018; aceptado: 27 de mayo de 2018; publicado: 27 de septiembre de 2018.

Revista Historia Autónoma, 13 (2018), pp. 103-124

DOI: https://doi.org/10.15366/rha2018.13.006

(c) (†) (8) 
Notas introdutórias

O significativo acervo de retábulos que ornam as igrejas de Minas Gerais, no Brasil, erguidas durante o século XVIII, suscitou a produção de incontáveis pesquisas que se dedicaram a analisar documentos e a elucidar a narrativa histórica que circundou a fábrica dessas peças. Contudo, ainda é inexpressivo o volume de investigações destinadas a examinar as temáticas que determinaram a efetivação da arte mineira colonial, em relação às referências gráficas que inspiraram as formações artísticas barroca e rococó luso-brasileiras. No amplo rol das alternativas de estudos pertinentes sobre essa matéria, acentua-se a necessidade de se delimitar as prováveis fontes utilizadas para extrair ideias, formas e estruturas que auxiliaram a confecção de projetos retabulares, refletindo aspectos estéticos e estilísticos relacionados às tendências correntes nos mais reputados centros europeus, sobretudo em Portugal.

Distingue-se que autores como Myriam Oliveira ${ }^{1}$, Alex $_{\text {Bohrer }}^{2}$ e Aziz Pedrosa ${ }^{3}$ mapearam fontes impressas que nutriram a criatividade dos homens envolvidos na fatura da talha mineira, elencando relações que intencionavam demonstrar como essas obras foram interpretadas para compor o plano ornamental dos retábulos. Apesar da ocorrência dessas prodigiosas contribuições, ainda são deficientes as pesquisas dedicadas a compreender esse conteúdo, principalmente se defrontadas às averiguações empreendidas a fim de fixar o protagonismo exercido por gravuras e tratados de arquitetura para a confecção da pintura de tetos das igrejas locais, que estabelecem resultados de vulto como bem exemplificam as investigações de Mateus Alves Silva ${ }^{4}$. Nesse sentido, este texto tem como orientação analisar o provável domínio do tratado de Andrea Pozzo para a elaboração da talha joanina em Minas Gerais, entre os anos de 1730 e 1760, considerando-se que os manuais elaborados pelo jesuíta, nesse período, circularam no universo artístico mineiro, como será detalhado adiante. À vista disso, espera-se que esta contribuição seja um debate de teor complexo e pouco investigado pela historiografia da arte que, por ora, começa a ser pormenorizado.

\footnotetext{
${ }^{1}$ Oliveira, Myriam Andrade Ribeiro de, O Rococó religioso no Brasil e seus antecedentes europeus, São Paulo, Cosac e Naify, 2003.

${ }^{2}$ Bohrer, Alex Fernandes, A Talha do Estilo Nacional Português em Minas Gerais: contexto sociocultural e produção artística, tese de doutorado, Universidade Federal de Minas Gerais, 2015.

${ }^{3}$ Pedrosa, Aziz José de Oliveira, A produção da talha joanina na capitania de Minas Gerais: retábulos, entalhadores e oficinas, tese de doutorado, Universidade Federal de Minas Gerais, 2016.

${ }^{4}$ Silva, Mateus Alves, O tratado de Andrea Pozzo e a pintura de perspectiva em Minas Gerais, dissertação de mestrado Universidade Federal de Minas Gerais, 2012.
} 


\section{Contextualização}

A partir da década de $1730^{5}$, despontaram nos retábulos da então Capitania de Minas Gerais orientações estéticas e formais relacionadas às influências oriundas da arte portuguesa setecentista, resultantes de empreitadas organizadas no correr do reinado de Dom João V, em que o Barroco italiano se tornou uma das referências basilares para as produções plásticas e arquitetônicas empreendidas pelo Monarca. A prosperidade da arte lusófona, decorrente desse ciclo, foi denominada por Robert Smith de "estilo joanino"6. Esse termo traduziu, acertadamente, a atmosfera dominante em Portugal na primeira metade do século XVIII, transformado pela importação da estética artística internacional, proveniente da circulação de publicações, objetos, artistas e arquitetos estrangeiros que impulsionaram apreciáveis desdobramentos para a cultura local ${ }^{7}$

Considera-se que a constituição formal e estética da talha portuguesa dessa fase foi favorecida pela circulação de tratados, gravuras e outros materiais impressos impregnados de representações gráficas, utilizadas como eixo condutor para que artistas e arquitetos pudessem atualizar seus repertórios ornamentais e referenciar a elaboração de traças para retábulos, consoantes às novidades que despontavam nas obras barrocas europeias. Essa interposição pode ser ratificada por intermédio da pesquisa de Maria da Graça Pericão ${ }^{8}$, responsável pela catalogação de número superior a 300 tratados de arte e arquitetura, pertencentes ao acervo da Biblioteca Nacional das Belas Artes (Lisboa), que, consoante às indicações proferidas pela autora, determinaram a formação dos artistas lusófonos ativos no século XVIII.

Entre os livros mais afamados no ambiente artístico português, durante o período de influência do estilo joanino, citam-se a obra do ornamentista Filippo Passarini, Nuove Inventioni ${ }^{9}$, publicada em Roma no ano de 1698; o tratado Architettura Civile do cenógrafo Ferdinando Galli Bibiena $^{10}$, que engloba ilustrações de molduras, portadas e outros elementos que também podem ter auxiliado a composição de retábulos; e o tão celebrado tratado de Andrea Pozzo, Perspectiva Pictorum et Architectorum, amplamente consultado por artistas e arquitetos, como relativizado por Magno Mello ${ }^{11}$.

\footnotetext{
${ }^{5}$ As pesquisas de Aziz Pedrosa indicam que, na Colônia brasileira, especificamente em Minas Gerais, a talha do estilo joanino abarcou um ciclo de 30 anos, estendendo suas manifestações até por volta do ano de 1760 . Pedrosa, Aziz José de Oliveira, A produção da talha joanina... op. cit., p. 31.

${ }^{6}$ Smith, Robert C., A talha em Portugal, Lisboa, Livros Horizontes, 1962, p. 86.

${ }^{7}$ Ferreira, Sílvia Maria cabrita Nogueira Amaral da, A talha dourada do altar-mor da Igreja de Santa Catarina, em Lisboa, dissertação de Mestrado, Universidade Lusíada de Lisboa, 2002, p. 14.

${ }^{8}$ Pericão, Maria da Graça, "Tratadística de Arte dos Séculos XVII e XVIII Existente na Biblioteca da Academia das Belas Artes de Lisboa", en Barroco, 15 (1990-1992), pp. 189-218.

${ }^{9}$ Passarini, Filippo, Nouve Inventione d'Ornamenti d' Architettura e d'Intagli di Versi utili ad argentieri intagliatori ricamatori et altri professori delle buone arte del disegno, Roma, 1698.

${ }^{10}$ Galli Bibiena, Ferdinando, L'Archittettura Civile: preparata sul a geometria e ridotta alle prospettive, Parma, Arnaldo Forni Editore, 1711.

${ }^{11}$ Mello, Magno Moraes, A pintura de tectos em perspectiva: no Portugal de D. João V, Lisboa, Estampa, 1998, pp. 233-238.
} 
Nas Minas Gerais dos setecentos, essas fontes, bem como outras não declaradas, podem ter sido empregadas como arquétipos para a produção de riscos retabulares. No entanto, esse tema é encoberto por sombras, principalmente porque pouco se conhece a respeito da permanência dessas publicações sob a posse de entalhadores e demais artífices que se dedicavam à confecção da talha mineira. Fragmentadas alusões, constantes em documentos que elencam bens pertencentes aos homens envolvidos na produção da arte e da arquitetura regional, clarificam algumas dessas indeterminações. Assim, memora-se o nome do carpinteiro Manuel Francisco de Araújo, atuante na construção religiosa da época em tela, cujo inventário identifica a posse de "um livro de arquitetura" título e do autor da referida obra, é possível que esse seja um manual de arquitetura, com detalhamento técnico e informações que auxiliavam o exercício da profissão.

Os pintores atuantes na então Capitania de Minas também mantiveram entre seus pertences interessantes bibliotecas, referências para a concepção de seus trabalhos. Nessa lista, encontra-se o pintor Caetano Luis de Miranda, ativo na região do Serro em fins do século XVIII e início do XIX, possuidor de impressionante quantidade de livros e estampas, entre eles dois objetos descritos como Prespectivas dos pintores in follio dois volumes ${ }^{13}$. Não foi discriminado o autor desses itens, porém a pesquisadora Camila Santiago ${ }^{14}$ sugeriu que fossem esses os dois volumes que compuseram o tratado do irmão jesuíta Andrea Pozzo, Perspectiva Pictorum et Architectorum, publicados nos anos de 1693 e 1700.

Além disso, é pertinente registrar a permanência dos tratados de Andrea Pozzo na biblioteca do Santuário do Caraça (Minas Gerais) que, apesar de desaparecidos, foram arrolados nas fichas remanescentes e identificados por Mateus Alves Silva ${ }^{15}$.

Constata-se que pouco se conhece a respeito da existência de livros sob a posse de entalhadores e outros oficiais envolvidos na fábrica da talha em Minas. Como exceção, apontase a pequena biblioteca de propriedade do entalhador lisboeta José Coelho de Noronha (17051765), que contemplava um caderno com "estampas que serviam de arquitetura" e "dois livros de arquitetura, primeira e segunda parte" ${ }^{16}$ que, seguramente, foram por ele consultados para auxiliar a geração de seu trabalho. Não foram relacionadas informações adicionais acerca das estampas, tampouco se pode especular o autor, o período ou o título dessa obra, uma vez que era significativa a quantidade de publicações destinadas à ornamentação no período. Entretanto, os livros de arquitetura, nenhum deles com autoria declarada no referido documento, despertaram a curiosidade de se conhecer os seus autores.

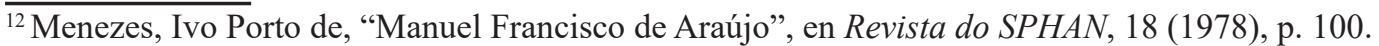

${ }^{13}$ Santiago, Camila Fernanda Guimarães, Uso e impacto de impressos europeus na configuração do universo pictórico mineiro (1777-1830), tese de doutorado, Universidade Federal de Minas Gerais, 2009, p. 153.

${ }^{14}$ Ibídem, p. 153.

${ }^{15}$ Silva, Mateus Alves, O tratado de Andrea Pozzo... op. cit., p. 76.

${ }^{16}$ Arquivo Técnico do Escritório II do Iphan, São João del-Rei, Inventário, 1765. Noronha, José Coelho de, caixa 345 , p. 21-21v.
} 
Nesse sentido, presumíveis esclarecimentos para essas hesitações foram difundidos nas pesquisas de Aziz Pedrosa ${ }^{17}$, que examinou os retábulos confeccionados por José Coelho de Noronha em Minas Gerais e elencou múltiplas relações das peças por ele faturadas, com informações que permearam os manuais formulados por Andrea Pozzo, demonstrando ser crível que os livros descritos em seu inventário eram, hipoteticamente, os volumes do tratado do irmão jesuíta, Perspectiva Pictorum et Architectorum. Admite-se, equitativamente, que essas referências podem ter sido manuseadas pelo entalhador durante a instrução recebida em Portugal, favorecendo o contato e as leituras de textos relacionados à tratadística em que o Pozzo foi um nome vastamente conhecido.

Diante desse breve painel, especifica-se a existência de escritos em Minas Gerais que beneficiaram o fortalecer da arte, potencializando a ampliação do repertório formal e estético dos artistas, por intermédio de obras que trouxeram, para o território colonial, a essência artística europeia, que também inflamava as oficinas de talha portuguesa. Assim, são esses vestígios os esteios elementares para os estudos que encabeçam este artigo e que permitem avaliar a irradiação da erudição no seio da talha mineira, legitimada por documentos que atestam a permanência dos tratados de Andrea Pozzo na biblioteca do pintor Caetano Luis de Miranda, dos livros de arquitetura do entalhador José Coelho de Noronha e dos impressos de posse de outros oficiais envolvidos na produção artística e arquitetônica local.

\section{A publicação de Andrea Pozzo, Perspectiva Pictorum et Architectorum}

O irmão jesuíta Andrea Pozzo (1642-1709) publicou, entre os anos de 1693 e 1700, os dois volumes que compõem o tratado de perspectiva para arquitetura e pintura: Perspectiva Pictorum et Architectorum. Neles, demonstrou recursos arquitetônicos e ornamentais profusamente empregados nas composições do Barroco romano, a partir dos anos finais do século XVII. Magno Mello ${ }^{18}$ sublinhou que Pozzo era um arquiteto autodidata, cujos enunciados propagados foram extraídos dos tratados italianos, circulantes nos séculos XVI e XVII. Tal interposição esteia respostas esclarecedoras acerca da obra do jesuíta, que pode ser compreendida como um manual integrado por recopilações de itens e feições constantes em outros livros manuseados para alicerçar suas formulações. Essas informações, no que se refere ao caráter formal e arquitetônico disseminado, não se constituíram em um exato compêndio imbuído de conteúdo original.

\footnotetext{
${ }^{17}$ Pedrosa, Aziz José de Oliveira, José Coelho de Noronha: artes e ofício nas Minas Gerais do século XVIII, dissertação de mestrado, Universidade Federal de Minas Gerais, 2012, p. 269.

${ }^{18}$ Mello, Magno Moraes, A pintura de tectos... op. cit., p. 234.
} 
Acrescenta-se a esse debate as análises realizadas por Mateus Alves Silva ${ }^{19}$, demonstrando que os livros divulgados por Andrea Pozzo veicularam fundamentos de perspectiva para a produção pictórica e arquitetônica, a partir de uma estruturação prática e compreensível que assegurava a imediata interpretação das ideias difundidas, organizadas por textos seguidos de ilustrações elucidativas. Assim, pode-se compreender que essa é a característica basilar do texto do Pozzo, responsável por assegurar a popularidade do conteúdo por ele elaborado no âmbito da arte, essencialmente no território das Minas Gerais setecentistas, onde não havia escolas ou centros destinados a doutrinar arte e arquitetura, habilitados a difundir a erudição necessária para qualificar e fundamentar as obras que eram empreendidas. Essa função tornavase competência das oficinas, que se converteram em núcleos destinados a gerir a formação de mão de obra, voltada a suprir as demandas locais.

Por esses entendimentos, observa-se que as propostas de Andrea Pozzo trouxeram a reedição da aplicação de elementos correntes na esfera arquitetônica, eliminando a geração de novas formas e concentrando a singularidade de suas criações no livre modo de se rearranjar conceitos consagrados pela arquitetura, sugerindo, aos que nele se referenciava, a liberdade para organizar os objetos de modos variados, direcionados pelo gosto e criatividade do projetista. Tais representações foram traçadas com a técnica de perspectiva, que permite criar, no plano bidimensional, ambientes ilusórios tridimensionais, por meio de linhas orientadas pela projeção espacial.

Proposições dessa natureza serviram aos oficiais que se encarregaram de idear o Barroco português e foram extensamente consultadas por arquitetos, pintores e entalhadores, principalmente durante as primeiras décadas do século XVIII, no decurso da vigência do estilo joanino. Observa-se que, no círculo da talha luso-brasileira, os desenhos de altares publicados por Pozzo emularam influências sentidas na estrutura, nas formas e nos ornamentos dessas peças, como exemplifica os projetos para o Altare de S. Ignatio e o Altare del B. Luigi ${ }^{20}$, em que avulta a configuração marcadamente arquitetônica, simulando a espacialidade produzida em um móvel erguido para ser alocado no interior do ambiente sacro. Elimina-se, assim, a possibilidade do tratamento apenas ornamental do retábulo, balizado por seções organizadas em base, banco, corpo e coroamento, com sistemática peculiar à estruturação das edificações clássicas.

No corpo dos supracitados altares gizados por Pozzo, as colunas simulam a sustentação do coroamento. Todavia, elas atestam apenas função alegórica, conferem destaque ao tramo central e acentuam efeitos de monumentalidade, uma vez que não são elementos estruturais como as colunas que, convencionalmente, amparavam a cobertura dos edifícios. O registro do coroamento foi dinamizado por figuras antropomórficas que, também, elevam o caráter teatral

\footnotetext{
${ }^{19}$ Silva, Mateus Alves. O tratado de Andrea Pozzo... op. cit., p. 68.

${ }^{20}$ Figura 60, Pozzo, Andrea, Perspectiva pictorum et architectorum Andreae Putei e societate Jesu, Pars secunda, Roma, 1758. Nota: A citação das figuras, nesta seção, corresponde à numeração apresentada nos dois volumes do tratado de Andrea Pozzo (exemplo: Figura 52).
} 
da seção, em que se sobressai a magnífica alegoria da Santíssima Trindade, como ilustra o projeto para o Altare de S. Ignatio ${ }^{21}$. Essa representação foi reproduzida nos retábulos mineiros do estilo joanino e do ciclo Rococó. É de consenso que o projeto em debate foi referência elementar para a escultura ornamental joanina em Minas; porém, nem todos os aspectos que determinaram a talha mineira dessa fase foram subsidiados nos princípios proclamados por Pozzo, apontando-se a abertura do camarim em profundidade e a instalação do trono escalonado em degraus, que individualizam feições da arte barroca de influência portuguesa.

Esses e outros efeitos determinantes nas figuras desenvolvidas por Andrea Pozzo indicam que sua publicação foi mostruário das possibilidades de manipulação de elementos arquitetônicos, permitindo ao Barroco a elevação de retábulos que reproduziram espacialidades, obtidas mediante ao arranjo de peças tridimensionais variadas. Essa tendência permitiu a Argan ${ }^{22}$ anunciar que, na arquitetura barroca, as colunas se integravam às cornijas, aos entablamentos e a sucessivos planos em busca de se produzir um ambiente visual monumental, em oposição à representação de um espaço apenas tectônico.

Tais conceitos foram incorporados aos retábulos, orientados por artimanhas controladas por efeitos de perspectiva que intencionavam desenvolver espaços arquitetônicos ilusórios, para articular a peça retabular e seus componentes alegóricos ao ambiente interno dos templos religiosos. Assim, as propostas expedidas por Pozzo seduziram os oficiais que nele referenciavam formas de dosséis, fragmentos de frontões, volutas e colunas que asseguravam a construção do volume arquitetônico e a definição da expressão plástica suscetível de transfigurar a estrutura das edificações e dos retábulos. Caráter semelhante foi indicado por $\operatorname{Argan}^{23}$ ao discorrer sobre a pintura de Pietro da Cortona (1596-1669), defendendo a ideia de que o pintor promovia a integração dos espaços imaginários pictóricos com as áreas reais da arquitetura. Essa especificidade foi igualmente apreciada nas obras faturadas por Gian Lorenzo Bernini (1598-1680), que magistralmente soube integrar o ornamento às edificações, em produções que notabilizaram o Barroco italiano.

Frisa-sequeformulaçõeshomônimasforamapreciadasnosempreendimentos desenvolvidos pelo Barroco religioso luso-brasileiro, em que as formas e as referências estéticas viabilizaram ao entalhador, em função de ornamentista, reorganizar o espaço interno dos templos, por meio da integração de adornos, engendrando construções fantásticas, sugestionadas no conteúdo gráfico dos impressos circulantes. Esse movimento foi fundamentado no princípio barroco de unidade e da integração da decoração à arquitetura; nele, a trama cenográfica dissimulava as dificuldades de se intervir em um ambiente que, na maioria dos casos, não era planejado em conjunto com a ornamentação e, habitualmente, era realizada em contextos diferentes daqueles que elevaram a caixa arquitetônica.

\footnotetext{
${ }^{21}$ Figura 62, Pozzo, Andrea, Perspectiva pictorum... op. cit.

${ }^{22}$ Argan, Giulio Carlo, Imagem e persuasão: ensaios sobre o barroco, São Paulo, Companhia das Letras, 2004, p. 122.

${ }^{23}$ Ibidem, p. 455.
} 
Atentos a esses objetos e aos ensinamentos provenientes de obras como o tratado de Andrea Pozzo, os entalhadores portugueses recorreram a entendimentos afins para produzir a talha dourada, em que o ornamento foi item essencial para as delimitações formais, estruturais e estéticas dessas peças. Tais efeitos eram desenvolvidos e aprimorados por intermédio dos oficiais de maior erudição, que mantiveram vínculos com o setor da construção e conseguiram imprimir, nos retábulos, conceitos essenciais da plástica arquitetônica barroca, em que a marcante disposição das massas procurava erigir espaços ilusórios, definidos pela sobreposição de planos e volumes embebecidos pela luz, que extremavam o drama barroco no interior dos templos sacros.

Desse modo, muitos entalhadores encontraram nas instruções propagadas por Andrea Pozzo modelos que lhes possibilitavam compreender as técnicas de se manipular unidades referenciadas na arquitetura e adaptá-las aos retábulos, em consonância com a sensível redução de escala do objeto retabular, se comparado ao porte, por vezes monumental, de uma edificação religiosa barroca. O emprego de técnicas de perspectiva para o desenho de formas, elementos arquitetônicos e escultóricos, determinados nos esboços do Pozzo, evidenciam fontes que serviram como repertório para a produção da talha colonial luso-brasileira.

\section{Os livros de Andrea Pozzo e a talha em Minas Gerais: alguns apontamentos}

Encontram-se, na talha joanina mineira, feições que, presumivelmente, foram extraídas dos supracitados tratados de Andrea Pozzo. Para inquirição dessa interposição, convida-se a perceber, inicialmente, a obra retabular confeccionada pelo entalhador lisboeta José Coelho de Noronha, uma vez conhecida sua biblioteca particular com livros de arquitetura que, hipoteticamente, são publicações atribuídas ao Pozzo.

Dentro dessas perspectivas, reforça-se a deferência do risco para o Altare de S. Ignatio ${ }^{24}$, elaborado por Andrea Pozzo, cujos feitios podem ter contribuído para a constituição estética e formal dos retábulos luso-brasileiros, faturados debaixo da estética do estilo joanino, no momento em que o programa artístico relacionado ao estilo nacional português foi atualizado, em conformidade com as novidades manifestadas no cenário das artes e da arquitetura hodiernas das produções do barroco italiano. Essas relações são conferidas no coroamento dos exemplares do ciclo joanino, provido de efeitos de dinamismo e de teatralidade, assegurados pela presença

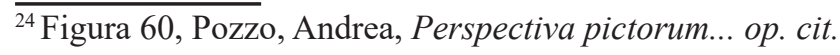


de relevos retratando a Santíssima Trindade, que permitiram estreitar correspondências entre a arte luso-brasileira e o supracitado projeto do Pozzo.

Nas igrejas de Minas, representações guiadas pela criação de Andrea Pozzo para o Altare de S. Ignatio são encontradas no conjunto escultórico integrado pelo Deus Pai, o Filho, a pomba do Espírito Santo e o globo simbolizando o mundo recém-criado (fig. 1), que compuseram o coroamento do antigo retábulo-mor da igreja Matriz de Santo Antônio (Santa Bárbara) ${ }^{25}$ (fig. 2). Esse admirável relevo foi desenvolvido por José Coelho de Noronha e a equipe que, em $1745^{26}$, esteve a cargo da elevação da referida obra e pode ter contado com a exímia colaboração do entalhador Francisco Xavier de Brito. O confronto dessa peça com a supracitada imagem, desenvolvida pelo Pozzo, estabelece afinidades constantes no desenho do mundo e das figuras antropomórficas, que se apresentam sem o cajado e a cruz nas mãos, mas que, certamente, existiram à época em que foram esculpidas. Conhecido o envolvimento de Coelho de Noronha na oficina que realizou a escultura em apreciação, torna-se aceitável especular que a referência para essa produção pode ter sido extraída dos livros de arquitetura que estavam sob sua posse. Acentua-se, desse modo, a possibilidade de ser a dita publicação o tratado de Andrea Pozzo.

Afora o exemplar escultural da igreja Matriz de Santo Antônio (Santa Bárbara), advertese que o relevo da Santíssima Trindade integrou outras peças retabulares mineiras, elencandose, entre essas, o retábulo-mor da igreja Matriz de Nossa Senhora da Conceição (Catas Altas), faturado por Manoel Gonçalves Valente, a partir de 1746; e o retábulo-mor da igreja Matriz de Nossa Senhora do Pilar (Ouro Preto), executado por Francisco Xavier de Brito, por volta de 1746.

Figura 1: Figura 60 do tratado de Andrea Pozzo, Pars seconda.

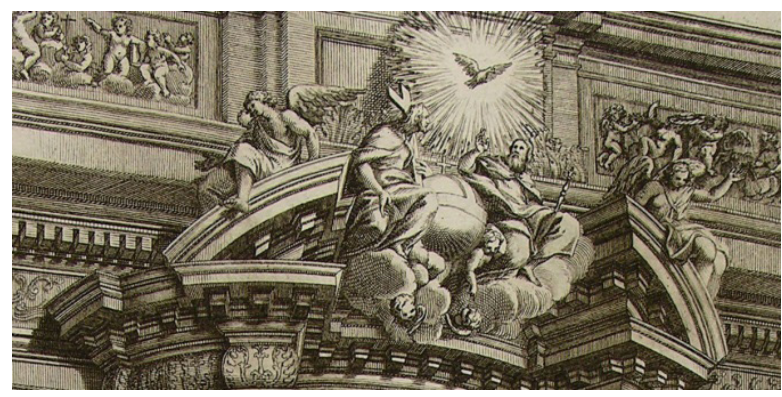

Fonte: Pozzo, Andrea, Perspectiva pictorum... op. cit.

\footnotetext{
$\overline{{ }^{5} \text { Os fragmentos }}$ desse retábulo encontram-se depositados no Museu da Inconfidência, em Ouro Preto, Minas Gerais, no Brasil.

${ }^{26}$ Pedrosa, Aziz José de Oliveira, A produção da talha joanina... op. cit., p. 213.
} 
Figura 2: Grupo escultórico Santíssima Trindade, Museu da Inconfidência, Ouro Preto (2011).

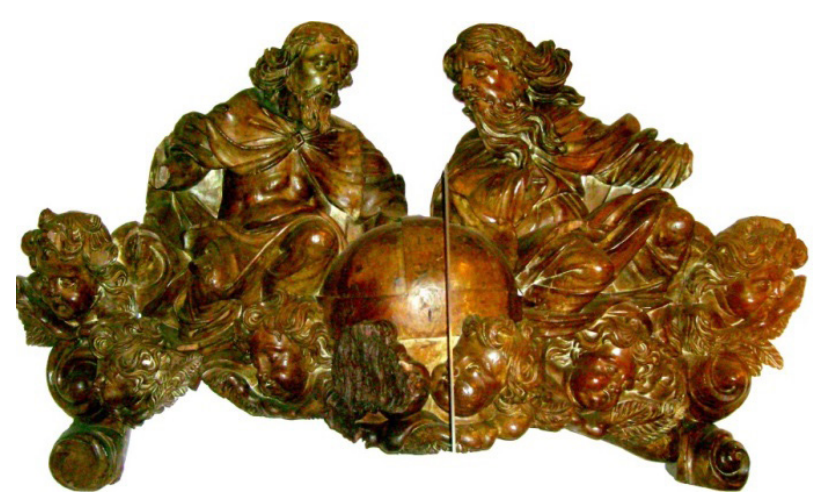

Fonte: Fotografia do autor.

Sequencialmente, prosseguindo as ponderações a que se destina este texto, reporta-se à figura de número $33^{27}$, divulgada por Andrea Pozzo, em que configuração correspondente é pontuada em exemplares retabulares joaninos mineiros que abrangem entablamento determinado por cornija denticulada e fragmentos de frontões sobre os quais repousam esculturas antropomórficas (fig. 3). Composições afins são vistas, exemplarmente, no retábulomor da igreja Matriz de Nossa Senhora da Conceição (Catas Altas). Não obstante, admite-se que repostas para a presumível circulação da indicada imagem do Pozzo na Capitania de Minas encontre aceitáveis respostas nos feitos orientadores da elaboração das seções que delimitam os retábulos complementares ao arco-cruzeiro da Catedral Basílica de Nossa Senhora da Assunção (Sé de Mariana), dedicados à Nossa Senhora da Conceição e a São José (figs. 4 e 5).

Figura 3: Figura 33 do tratado de Andrea Pozzo, Pars prima.

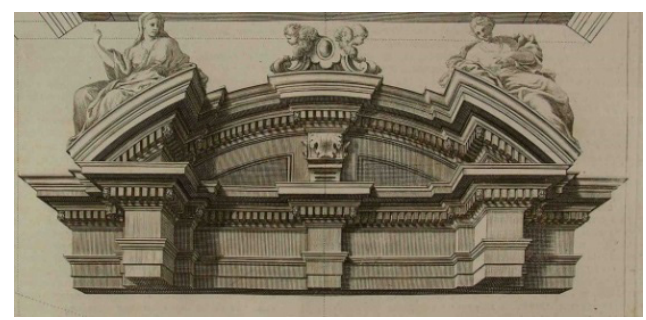

Fonte: Pozzo, Andrea, Perspectiva pictorum... op. cit.is[e-pi

\footnotetext{
${ }^{27}$ Figura 33, Pozzo, Andrea, Perspectiva pictorum... op. cit.
} 
Figura 4: Coroamento do retábulo de Nossa Senhora da Conceição, Sé de Mariana (2011).

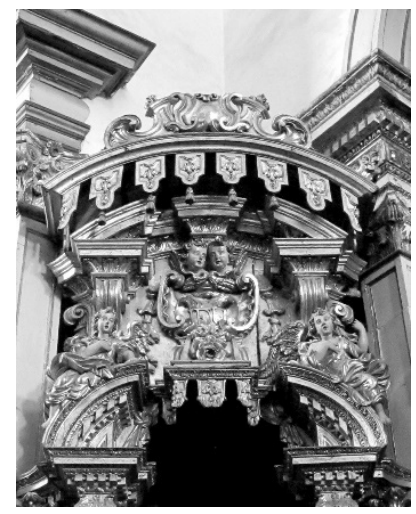

Fonte: Fotografia do autor.

Figura 5: Retábulo de Nossa Senhora da Conceição, Sé de Mariana (2011).

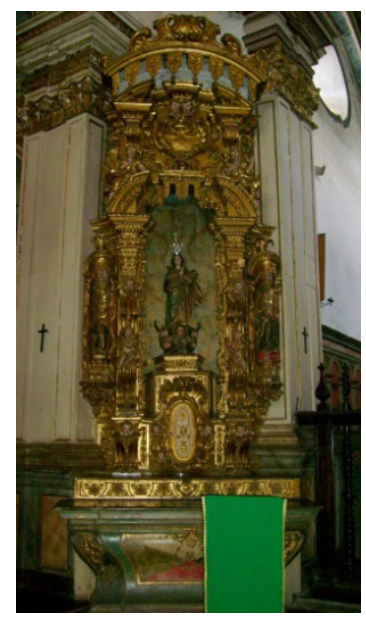

Fonte: Fotografia do autor.

Os registros históricos explicitam que o aludido retábulo de Nossa Senhora da Conceição foi produzido por José Coelho de Noronha, em $1747^{28}$. Não foi localizada documentação que determine a oficina que esteve à frente da fatura do exemplar de São José, mas as semelhanças plásticas entre essas duas peças retabulares autoriza atribuir ao Noronha a efetivação de sua talha. Para além desses pormenores, chama-se a atenção para a possibilidade da figura de número $33^{29}$, riscada por Andrea Pozzo, ter servido como inspiração para a elaboração das formas que integram os espécimes em exame. Essa conjectura é amparada no idêntico posicionamento das esculturas antropomórficas sentadas sobre os fragmentos de frontões e na gestualidade que expressam, diferindo-se, apenas, a aplicação de alguns motivos ornamentais e o emprego de

\footnotetext{
${ }^{28}$ Pedrosa, Aziz José de Oliveira, A produção da talha joanina... op. cit., p. 213.

${ }^{29}$ Figura 33, Pozzo, Andrea, Perspectiva pictorum... op. cit.
} 
asas (figs. 6 e 7), assinalando interpretações do escultor que as executou, não presentes no projeto do Pozzo em evidência.

Curiosamente, antecede à sanefa dos retábulos de Nossa Senhora da Conceição e São José (fig. 4) aparente composição de procedência arquitetônica, constituída por formas que podem ter sido inspiradas no mencionado desenho de Andrea Pozzo (fig. 3). Nos casos em estudo, a instalação desses recursos viabilizou a eliminação do habitual dossel com cortinado que, entre os anos de 1730 e 1745, ocupou essa seção dos retábulos fabricados em Minas. A adição desses ornatos permitiu elevar o pé-direito da unidade retabular, dinamizando o registro com a instalação de um plano definido por construções que edificaram a simulação de uma espacialidade, perspectivada para a seção na qual se encontram.

Figura 6: Pormenor do coroamento do retábulo de São José, Sé de Mariana (2011).

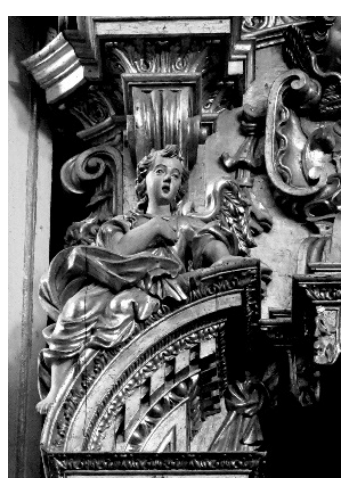

Fonte: Fotografia do autor.

Figura 7: Pormenor da Figura 33 do tratado de Andrea Pozzo, Pars prima.

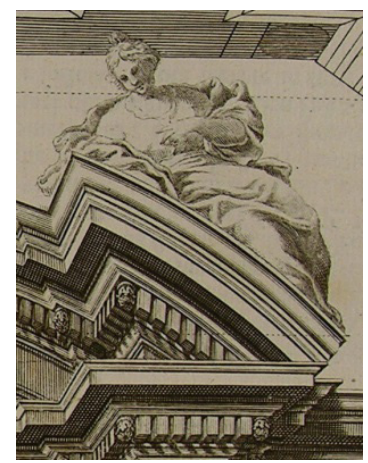

Fonte: Pozzo, Andrea, Perspectiva pictorum... op. cit.

Em conformidade com as amplas alternativas para o estudo das relações entre a obra de Andrea Pozzo e a talha mineira, avivam-se as mísulas que compõem os bancos dos retábulos de Nossa Senhora da Conceição e de São José, pertencentes à Sé de Mariana. As mísulas 
são itens presentes nos retábulos de Minas desde os modelos associados ao estilo nacional, permanecendo nas obras joaninas e rococós, diferindo-se certas formas e ornamentos que individualizam as abordagens plásticas e especificaram cada contexto artístico no qual foram elaboradas. Nos exemplares em exame, as mísulas que os compõem designam afinidades aos desenhos representados nas figuras 106 e 107, riscadas para o tratado de Andrea Pozzo ${ }^{30}$, cujas relações são verificadas na presença da cabeça de anjo do arremate, nos relevos centrais em formato circular, no enrolamento superior e inferior que finalizam a peça, incluindo-se a folha de acanto comparável à que é sugerida na mencionada ilustração (figs. 8, 9 e 10). As paridades entre as obras lavradas por Noronha e os desenhos veiculados por Pozzo são suscetíveis de sinalizar a fonte que serviu de sugestão para o dito entalhador realizar esses trabalhos.

Figura 8: Figura 106 do tratado de Andrea Pozzo, Pars seconda.

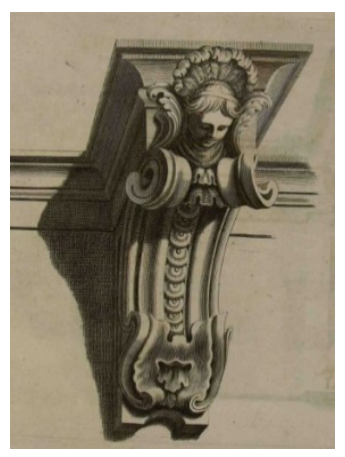

Fonte: Pozzo, Andrea, Perspectiva pictorum... op. cit.

Figura 9: Figura 107 do tratado de Andrea Pozzo, Pars seconda.

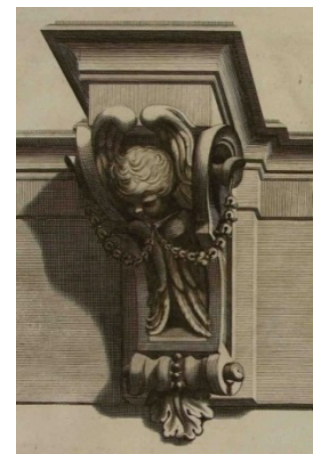

Fonte: Pozzo, Andrea, Perspectiva pictorum... op. cit.

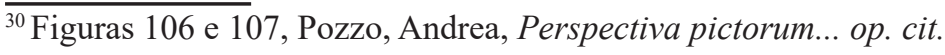


Figura 10: Mísula do retábulo de Nossa Senhora da Conceição, Sé de Mariana (2011).

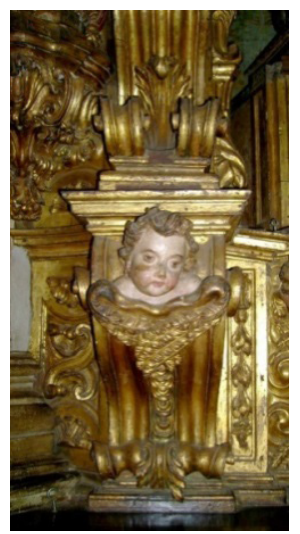

Fonte: Fotografia do autor.

Modelos semelhantes compuseram dezenas de retábulos joaninos erguidos nas igrejas de Minas, ao longo de 1730 e 1740, em que as mísulas envolviam figuras antropomórficas que exerceram a função de atlantes, simulando suporte para as colunas que estruturavam o registro do corpo, como conferido no distinto retábulo-mor da igreja Matriz de Nossa Senhora do Pilar (Ouro Preto). Nos exemplares produzidos a partir da década de 1750, essas esculturas foram substituídas por cabecinhas de anjos alocadas na porção superior da mísula, em similitude aos supracitados desenhos de Andrea Pozzo. Interpretações afins são identificadas no retábulo principal da igreja Matriz de Nossa Senhora do Pilar (São João del-Rei), executado por José Coelho de Noronha e a oficina que com ele laborou entre 1755 e $1758^{31}$.

No campo da talha portuguesa, mísulas congêneres adornam o retábulo de Nossa Senhora do Rosário da igreja do Convento de Nossa Senhora do Bom Sucesso (Lisboa), datado de 1746 e faturado pelo entalhador Manuel Barbuda ${ }^{32}$. É relevante registrar que essa peça retabular evoca outros itens que podem ter sido referenciados nas figuras produzidas por Andrea Pozzo, fator esse que também sinaliza o prestígio das publicações do irmão jesuíta no âmago da talha luso-brasileira.

Sem embargo, é imperativo sublinhar que, nos altares desenhados por Andrea Pozzo, as mísulas não serviram de embasamento para colunas e outros adereços que indicavam a estruturação do objeto retabular, como generalizado nos protótipos luso-brasileiros. Distingue-se que Pozzo recorreu a essas representações objetivando transformar as composições e projeções desenvolvidas para pintura de tetos, em que esses adornos eram aplicados como suporte para as colunas, de modo a construir e organizar o plano arquitetônico pictórico, como indica a imagem

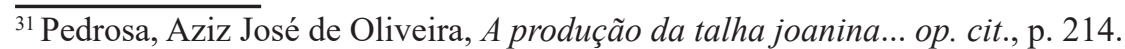

${ }^{32}$ Ferreira, Silvia, A talha: esplendores de um passado ainda presente (sec. XVI-XIX), Lisboa, Editora Nova Terra, 2008, p. 89.
} 
de número 59 desenvolvida pelo tratadista ${ }^{33}$. Ademais, memora-se que, nos retábulos joaninos de Minas, modelos de mísulas ornaram elegantes pilastras de desenho sinuoso, denominadas de quartelões, largamente inseridas nos espécimes coetâneos, como expressa o retábulo-mor da igreja Matriz de Nossa Senhora do Pilar (Ouro Preto), onde esses elementos se encontram conjugados com as colunas de tipologia salomônica, organizando os tramos externos.

Figura 11: Retábulo-mor, Matriz de Nossa Senhora do Bom Sucesso, Caeté (2017).

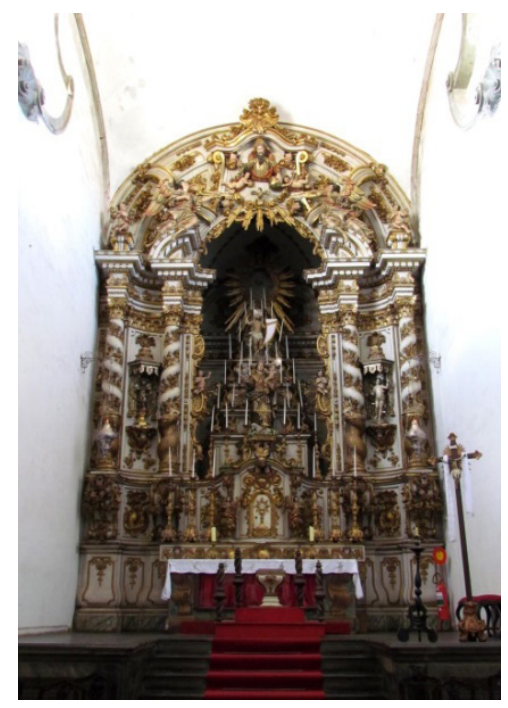

Fonte: Fotografia do autor.

Regressando-se ao aludido projeto de Andrea Pozzo para o Altare del B. Luigi ${ }^{34}$, confere-se que foi salientado o caráter arquitetônico da obra por intermédio da movimentação reentrante da base, visivelmente prolongada às demais seções do retábulo; pelo uso de pares de colunas torsas que alongaram o registro do corpo; pela sequência de volumes sobrepostos que determinam o entablamento, cujos arranjos evidenciam a sobrepujada delimitação espacial das peças; e, sobretudo, pela elevação do coroamento organizado por junções dinâmicas, elementos arquitetônicos e figuras antropomórficas sentadas sobre fragmentos de frontões que realçam o esquema da arquitetura e da produção teatral, formando o conjunto retabular.

As ideias contempladas na referida ilustração do Pozzo permearam as intepretações de José Coelho de Noronha para a edificação da estrutura, da forma e da plástica que abrangem as obras por ele executadas, constatadas nos retábulos-mores das igrejas Matrizes de Nossa Senhora do Bom Sucesso (Caeté 1758-1765) (fig. 11) e de Nossa Senhora do Pilar (São João del-Rei, 17551758) (fig. 12) ${ }^{35}$. É de mérito destacar que, para a traça do remate desses exemplares, Coelho

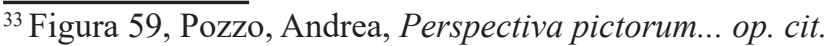

${ }^{34}$ Figura 62, Pozzo, Andrea, Perspectiva pictorum... op. cit.

${ }^{35}$ Nesses dois retábulos-mores, comprovadamente, José Coelho de Noronha atuou na fábrica da talha.
} 
de Noronha pode ter usufruído de sugestões pontuadas na supracitada figura desenvolvida por Andrea Pozzo, principalmente para o modelo retabular da igreja de São João del-Rei, em que a elevação da verticalidade, desfavorecida pelo baixo pé-direito da capela-mor, foi resolvida com o extravasamento do remate para além do arco-pleno, em demonstração análoga à proposta emitida por Pozzo. O aproveitamento desses artifícios sintetizam a destreza técnica e o apuro estético do entalhador, que se deparou com os problemas de uma edificação não planejada em conjunto com a ornamentação, exigindo habilidades que o capacitasse a rearranjar formas que gerassem impactos harmônicos visuais condizentes com a beleza da obra de talha que produzia.

A impressão da verticalidade à peça retabular ressoou em outros trabalhos processados por José Coelho de Noronha, cujos feitios podem ter sido absorvidos das ilustrações produzidas por Andrea Pozzo. Memora-se o fato de a documentação indicar que o entalhador efetuou modificações no retábulo de São Miguel e Almas, da Sé de Mariana, para alongar seus pilares, de modo que se apresentassem com maior perfeição ${ }^{36}$. A promoção desse efeito foi obtida com a instalação de colunas torsas, semelhantes em forma e volume àquelas desenhadas por Pozzo para compor a figura de número 62 (fig. 13) ${ }^{37}$, examinada neste trecho.

Figura 12: Retábulo-mor, igreja Matriz de Nossa Senhora do Pilar, São João del-Rei (2017).

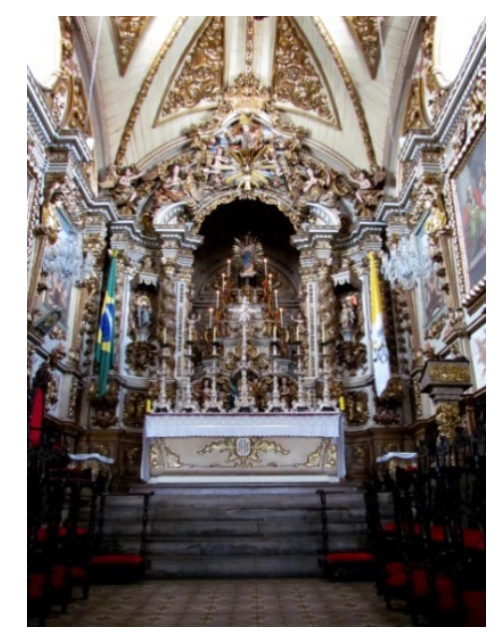

Fonte: Fotografia do autor.

\footnotetext{
${ }^{36}$ Arquivo da Casa Setecentista de Mariana, Ações cíveis, Códice 251, Auto 6217, Cartório do $2^{\circ}$ ofício, p. 34.

${ }^{37}$ Figura 62, Pozzo, Andrea, Perspectiva pictorum... op. cit.
} 
Figura 13: Figura 62 do tratado de Andrea Pozzo, Pars secunda.

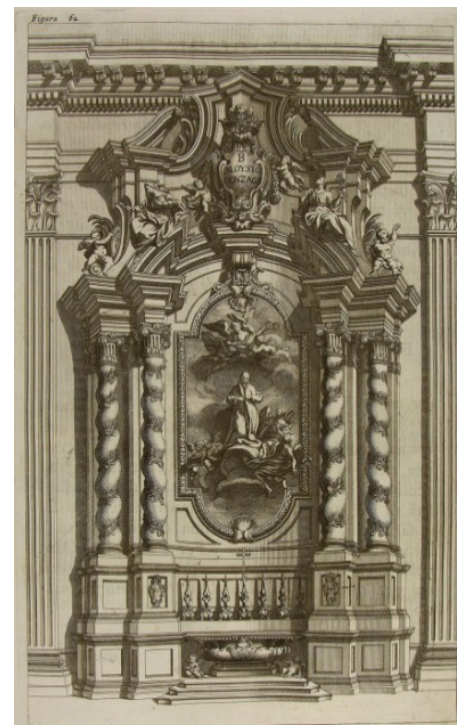

Fonte: Pozzo, Andrea, Perspectiva pictorum... op. cit.

As influências descendentes dos desenhos efetuados por Andrea Pozzo são percebidas em outras peças de talha joanina, que complementam a decoração das igrejas de Minas. Essas manifestações são compreendidas como quocientes da circulação das publicações do tratadista no universo artístico setecentista, conforme delimitado no início deste texto. Soma-se a isso a irradiação de conhecimentos advindos desses livros, por intermédio do saber acumulado pelos artífices portugueses, que obtiveram formação em Portugal e aclimataram o repertório visual e técnico que conheciam na Colônia, sendo essa uma significativa artéria para disseminação dos conteúdos correlatos à plástica artística e arquitetônica presentes nos retábulos mineiros.

Esse entendimento proporciona compreender como foi expressiva a relação das novas ideias formais que as publicações em inspeção trouxeram para a arte da talha em Minas. Nesse horizonte, evocam-se as figuras de números 15 e 81 do livro de Andrea Pozzo ${ }^{38}$, que descrevem motivos caracterizadores da ornamentação religiosa joanina mineira, em que a região dos arcos-cruzeiros das igrejas abrigam cartelas delineadas por ornatos curvilíneos, enrolamentos, palmetas e figuras antropomórficas aladas esvoaçantes, que elevaram a tônica cenográfica barroca desses ambientes, rompendo a rigidez dos elementos arquitetônicos onde se encontram. Nas igrejas de Minas Gerais, abundaram-se exemplares congêneres no arco-cruzeiro da Matriz de Nossa Senhora do Pilar (Ouro Preto), da igreja de Santa Efigênia (Ouro Preto), da Matriz de Nossa Senhora do Pilar (São João del-Rei) (fig. 14), da Matriz de Santo Antônio (Tiradentes) e da capela de Nossa Senhora do Rosário (Ouro Preto). Nas tarjas das igrejas ouro-pretanas supracitadas, coexistem coroas na composição, aproximando-se da proposta constante no projeto 81 traçado por Pozzo.

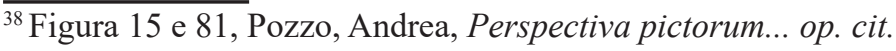


Todavia, mesmo diante de uma possível referência advinda da publicação de Andrea Pozzo, é basilar registrar que essas cartelas podem ter sido difundidas por outras gravuras, disseminadas no meio artístico luso-brasileiro setecentista. Isso também realça o caráter compilador das imagens que integram os livros de Andrea Pozzo, uma vez que ele, certamente, conheceu adereços equivalentes presentes em obras barrocas italianas, que podem ter servido como parâmetro para seus desenhos. Assim, é legítimo assinalar que tais ornatos foram exemplarmente empregados por artistas de indiscutível projeção, como Gian Lorenzo Bernini, que instalou, no ático da Scala Regia do Vaticano (1663-1666) ${ }^{39}$, cartela similar e, seguramente, potencializou o imaginário de uma geração de artistas conhecedora dessa intervenção, de onde podem ter extraído ideias para seus trabalhos.

Figura 14: Cartela, igreja Matriz de Nossa Senhora do Pilar, São João del-Rei (2017).

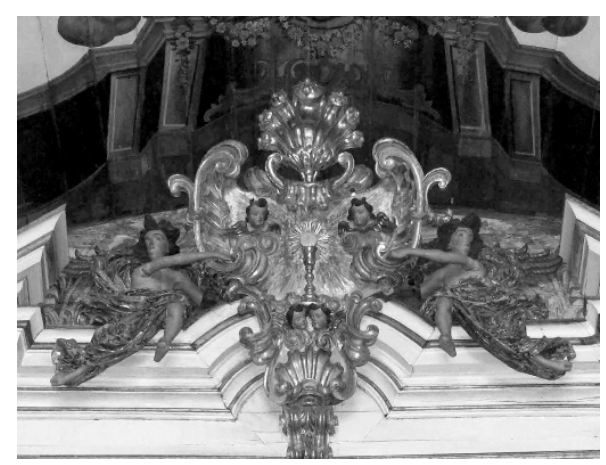

Fonte: Fotografia do autor.

Discorridas essas questões, focaliza-se a figura $64^{40}$ preparada por Andrea Pozzo, onde há sacrário em formato de urna, homogêneo ao mesmo item que integra o retábulo-mor da igreja Matriz de Nossa Senhora da Conceição (Catas Altas) (fig. 15). As paridades entre a referida peça e o desenho do tratadista não se restringem à forma, mas se estendem à análoga aplicação de relevos, motivos curvilíneos, esculturas antropomórficas e até mesmo do arremate em palmeta. O desenho ímpar desse sacrário, entre os modelos propagados nos retábulos joaninos de Minas Gerais, exige a delimitação de possíveis fontes que orientaram o autor dessa obra a construir esses formatos. Essas correlações, acrescentada da ciência da permanência dos livros de Andrea Pozzo no domínio da arte mineira, propiciam suster a hipótese de ter sido essa uma provável orientação para a execução do serviço em pauta.

\footnotetext{
${ }^{39}$ Wittkower, Rudolf, Arte y Arquitetctura en Italia: 1600-1750, Madrid, Ediciones Cátedra, 2010, p. 192.

${ }^{40}$ Figura 64, Pozzo, Andrea, Perspectiva pictorum... op. cit.
} 
Figura 15: Sacrário, retábulo-mor da Matriz de Nossa Senhora da Conceição, Catas Altas (2018).

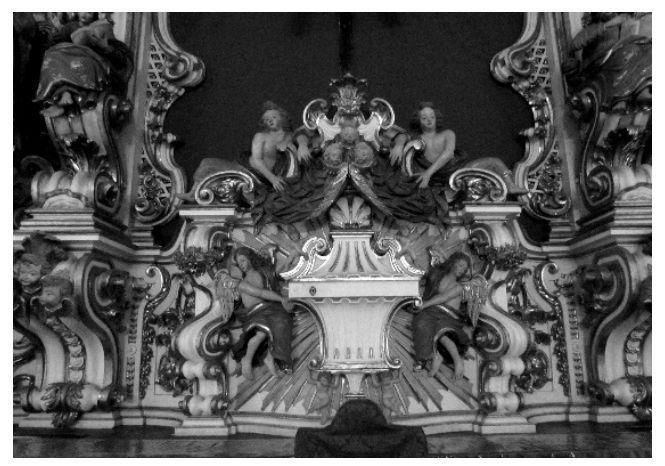

Fonte: Fotografia do autor.

Entretanto, é inusitado constatar que desenho correlato para sacrário não tenha sido comum no contexto da talha joanina em Minas, visto que esse foi um formato profusamente aplicado na arte barroca italiana, apreciado na Tomba di Leone XI, alocada na Basilica di San Pietro (Roma), produzido por Alessandro Algardi em 1634-1644. Essa representação repercutiu em outras obras italianas que avançaram o século XVIII, citando-se a Tomba di Papa Gregorio XIII, realizada por Camillo Rusconi, também exposta na Basilica di San Pietro, datada de 1719-1729. Outro exemplo que ratifica esse ponto de vista é a Tomba di Papa Benedetto XIII, concebida em 1743, por Pietro Bracci, pertencente à igreja de Santa Maria Sopra Minerva ${ }^{41}$. Além disso, elencam-se as gravuras publicadas por Filippo Passarini ${ }^{42}$ que trazem interpretações de urnas equivalentes, reafirmando a impetuosa presença da configuração desse elemento nas obras barrocas.

Indica-se que, para elaborar a figura de número $64^{43} \mathrm{em}$ apreciação, Andrea Pozzo possa ter se referenciado em alguns conjuntos escultóricos acima arrolados ou em tantas outras obras que versam sobre temática proporcional, incluindo-se textos destinados a discutir conteúdos relacionados à arte e à arquitetura, difundidos à época. Esse entendimento permite enfatizar o enunciado de que o tratadista jesuíta, para constituir seu manual, analisou e se inspirou em fontes diversas que permeavam o cenário artístico e arquitetônico do Barroco italiano. Todavia, essas deduções não excluem a hipótese aventada de que o modelo de sacrário encontrado no retábulo-mor da Matriz de Nossa Senhora da Conceição (Catas Altas) possa ter sido uma menção extraída das páginas do tratado do Pozzo, considerando-se sua sinalizada circulação entre as oficinas dedicadas a produzir a ornamentação interna das igrejas setecentistas de Minas, bem como as relações de paridade que permeiam e distinguem as peças em debate.

\footnotetext{
${ }^{41}$ Wittkower, Rudolf. Arte y Arquitetctura en Italia... op. cit., pp. 269 e 299.

${ }^{42}$ Passarini, Filippo. Nouve Inventione d'Ornamenti... op. cit.

${ }^{43}$ Figura 64, Pozzo, Andrea, Perspectiva pictorum... op. cit.
} 
Por fim, é de dever grifar os copiosos pormenores que preenchem os retábulos mineiros representantes do estilo joanino, sujeitos a ser detectados nas ilustrações difundidas por Andrea Pozzo, permitindo considerar que seu tratado exerceu sobressaltada predominância no imaginário dos entalhadores em exercício no período. A consistência dessa inferência é legitimada diante da ciência de que as publicações do irmão jesuíta podem ter sido mostruários circulantes nas oficinas dedicadas à produção da talha na Capitania de Minas Gerais. Entretanto, esse conteúdo foi insuficientemente examinado e encontra-se por ser desvendado e privilegiado em pesquisas que tenham a orientação de distinguir como foram absorvidas e interpretadas, nas obras retabulares, as demonstrações expedidas pelo Pozzo, visto que nem sempre a formatação dos retábulos explicita esse aspecto, quando muito anunciam feitios ornamentais sugerindo, por meio de suas formas ou por seu modo de organização nas composições retabulares, que os artistas envolvidos nesses serviços fizeram uso ou detinham memória da obra do jesuíta.

Alicerçados nessas perspectivas, os escassos estudos produzidos acerca do tema não possibilitam esclarecer como foram difundidas as formulações constantes nesses livros entre os homens encarregados de esboçar os retábulos e gerir as atividades dedicadas a erguer tais objetos que ornam as igrejas setecentistas de Minas Gerais. Sabe-se, em razão das raras menções documentais descobertas, que essas publicações eram objetos de posse dos artistas e arquitetos que operaram na então Capitania. Porém, ainda é necessário pormenorizar, por meio de ampla investigação, o modo como, de fato, esses oficiais utilizavam as referências extraídas dessas fontes, se apenas rearranjavam os motivos ornamentais visualizados nesses livros, a partir de orientações atreladas ao gosto pessoal, se atendiam às demandas expedidas pelos mecenas contratantes dos serviços, ou se eram motivados por fundamentações de natureza teórica, embasada nos repertórios plástico e estético, assimilados quando ainda viveram em Portugal, que lhes possibilitou erguer conceitos afeitos aos moldes extraídos desses tratados e aclimatálos nas terras coloniais brasileiras. Essas respostas não são encontradas, diante do silêncio dos registros históricos que nada especificam.

Seguramente, conforme os estudos emendados pelo autor deste artigo ${ }^{44}$, as peças retabulares que preenchem os ambientes internos dos templos de Minas, elaboradas a partir das referências do estilo joanino, não reproduziram, exatamente, as ideias subsidiadas nas imagens veiculadas na tratadística, em similar expressão ao Altare di Sant'Ignazio di Loyola, da igreja romana de Gèsu, que foi faturado em fiel concordância à figura traçada por Andrea Pozzo: Altare de S. Ignatio ${ }^{45}$.

No específico caso dos retábulos joaninos mineiros, é perceptível a permanência de formas e feitios que compuseram os tratados do Pozzo, embora não se possa delimitar que

\footnotetext{
${ }^{44}$ Pedrosa, Aziz José de Oliveira, A produção da talha joanina... op. cit.

${ }^{45}$ Figura 62, Pozzo, Andrea, Perspectiva pictorum... op. cit.
} 
houve o compromisso de se copiar, fielmente, as ideias do tratadista tal como elas foram por ele apresentadas. Certamente, esse fenômeno é decorrente da realidade mineira, que foi diversa daquela existente na Roma barroca, na Lisboa joanina e em tantos espaços europeus, onde a ornamentação sacra se converteu de particularidades distantes daquelas que engendraram as igrejas de Minas. Como possível entendimento para o caso, pensa-se que essas edificações religiosas sofreram delimitações circunstanciadas pelas condições técnicas, pela qualificação da mão-de-obra e pelos materiais disponíveis que, incondicionalmente, direcionaram a fábrica e a plástica dos retábulos de madeira da região mineira.

\section{Notas Finais}

Envolvido nesse espectro, discorreram-se algumas elucubrações que intentaram relativizar a possível influência exercida pelo tratado Perspectiva Pictorum et Architectorum, elaborado por Andrea Pozzo, para a remodelação da estrutura, das formas e dos ornamentos que compõem os retábulos do estilo joanino em Minas Gerais, faturados entre as décadas de 1730 e 1760. Essa temática, insuficientemente averiguada pela historiografia da arte, neste texto foi merecedora de atenção, perante o conhecimento de que as publicações do Pozzo estiveram em circulação na Capitania mineira, embora sejam escassas e incompletas as informações que abrangem o assunto, diante das lacunas não preenchidas pela documentação histórica que não foi, até este momento, habilitada a esclarecer as inumeráveis dúvidas que permeiam o assunto. Essa é uma das maiores dificuldades para a prosperidade das investigações que devem respostas e formulações ainda por serem produzidas.

Nesse sentido, os exames discorridos demonstraram grupos de referências delineadoras da composição de exemplares retabulares presentes nas igrejas de Minas, que podem ter sido extraídas dos dois volumes do tratado de Andrea Pozzo. Embora não seja verossímil que tenha sido essa a única fonte de inspiração para a arte da talha, visto ser consensual a existência de outros impressos à disposição dos artistas ativos na citada Capitania mineira, concorrendo para alicerçar a configuração estética da arte na região, como comprova o inventário do pintor Caetano Luiz de Miranda, indicando ser ele possuidor de dezenas de estampas ${ }^{46}$ utilizadas para a concretização do ofício que exercia.

Além disso, considera-se que a ascendência das formas e das estruturas advindas do contexto artístico português do ciclo joanino, inebriadas pelas referências oriundas do Barroco

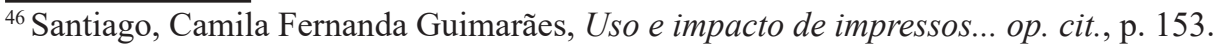


italiano, foi o espírito condutor para a produção retabular, em que o tratado examinado, seguramente, embasou o desenho de esculturas, direcionou a estruturação dessas peças e demonstrou a força presente no uso de construções perspectivadas para a delimitação e a construção de espacialidades simuladas que transformavam o interior das edificações e auxiliavam a manutenção da lógica barroca joanina, calcada em aspectos teatralizantes que dominaram a escultura ornamental coeva. Essas interposições são possíveis diante da conhecida presença dos tratados de Andrea Pozzo em Portugal, provavelmente fonte de consulta para os artistas que, no então Reino português, obtiveram formação e, posteriormente, mudavam-se para a Colônia onde exerciam sua arte. 